\title{
Nanoparticle Ferrite Multilayers Prepared by New Self-Assembling Sequential Adsorption Method
}

\author{
Yeong II Kim, ${ }^{*}$ Hojun Kang, Don Kim, and Choong Sub Lee ${ }^{*} \dagger$

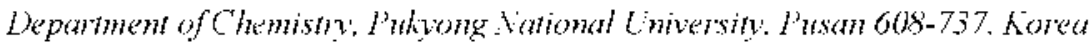

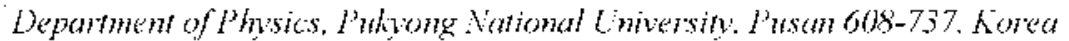 \\ Received June 1, 2002
}

\begin{abstract}
The nanoparticle magnetite ol which diancter was about $3 \mathrm{~mm}$ was synthexised in a homogencous aqueous solution without a template. The swnthesized magnetite nanoparticle was casily oxidized to maghemite in an ambient condition. The magnetic properties of the lenite nanoparticle show superparamagnetism at room temperatun and its blocking temperature is around $93 \mathrm{~K}$. Modifying the sequential adsorption method of metal bisphosphonate. we have prepared a multilayer thin film of the ferrite nanoparticle on planar substrates such as glass, quart\% and Si water. In this multilayer the lemile nanoparticle layer and an alky lbisphosphonate laver are altemately placed on the substrates by simple immersion in the solutions of the lemite nanopartick and 1 , 10-decanediylbis (phosphonic acid) (DPPA), altematcly. This is the lirst example as lar as we know, of nanoparticle/alkyl-bisphosphemate multilayer which is an analogy of metal hisphosphonate multilayer. UJVvisiblis absoption and infrared rellection-absoption studies show that the growth of each layer is very systematic and the film is considerahly optically transparent to visible light of $400-700 \mathrm{~mm}$. Atomic force microscopic images of the film show that the surlace moppology of the film follows that of the substrate in $\mu$ m-scale image and the nanoparticle-teminated surlace is dillerentiated from the DВPA-teminated one in nm-scale image. The magnetic properties of this lerrite/DЗРА thin liln are almost the sane as those of the limrite nanoparticle powder only:
\end{abstract}

Key Words : Magnetite, Nanoparticle, Metal bisphosphonate, Self-assembly

\section{Introduction}

The innestigation and preparation of nanosized and nanostructured matcrials lave recently become a very cxciting area of fundamental and applicd researches in chemisıy and material sciences. 'Since nanoparticles often have novel propertics that are different from those of bulk matcrials duc to their small size. they are becoming a core component of adranced matcrials that have wide practical applications witl noble optical. clcctrical. magnetic. and catalytic propertics.' Organic/inorganic hybrid thin film based on inorganic manoparicles is one of stimulating nanostructured materials. ${ }^{3}$ Laycr-by-layer growth of nanoparticles is a very prospective stratcgy for preparing manostructured tlin films since it can give a finc control over the incorporated components and the thick mess of film on a varicty of surfaces.

There are some reported techniques for preparing nanoparticle-incorporated multiplayer thin fim wliclı can be grown laỵcr-by-layer: Langmuir-Blodgett(L-B) mothod." polycecctrolytc melhod." and alkyl dithiol mothod. ${ }^{5}$ L-B melhod is the oldest and well-cslablished multiplayer teclinique. Howerer this melhod requires a number of plrysical manipulations in order to transfer a layer preassembled by meclanical force to a substrate. and the prepared film is themodynamically unstable. The polyclectrolyte and dithiol melhods utilize self-assembly belween a nanoparticle

"lo whom correspondence should be addressed. e-mail: vkim ' $\hat{l}^{\prime}$ phinu.ac.hr (Yeoung II Kim): csleciodpknu.ac.kr (Choong Sub Lec) and a cross-link molcculc. Among the sclf-asscmbling multiplayer tccliniques. there is a metal bisphosphonate multiplayer technique which is developed by Mallouk et al ${ }^{*}$ This multiplayer thin film is structurally very similar to L-B film but is thermody namically more stable and mechanically robust than L-B film because the metal ions are chemically coordinated to interlayer cross linkers of bisphosphonates.

Recent reports showed that phosphonate derivatives were strongly adsorbed on the surface of metal oxide such as $\mathrm{TiO}_{2}$ through the surface chelation of phosphonate. Utilizing this surface chelation of phosphonate. it may be possible to stepwisely stack metal oxide nanopanticles using an alkyl bisphosplionate as an interlayer cross-linking agent as shown in gold nanoparticle multiplayer by the dithiol method. ${ }^{6}$ In this casc. Inctal oxide nanoparticles will replace melal ions in a metal bisphosphonale multiplayer. Therefore. we present here new layer-by-layer slacking method of inorganic metal oxide and organic alkyl chain utilizing the surface chclation of phosphonate functional group to melal oxide surface. For this study. we used magnetic nanoparticles sirnce they are of great interest for wide praclical applications ${ }^{1 !}$ in information storage sysicms. catalyst. color imaging. ferrofluid. and medical diagnostics. First. We have synthesized and characterized magnetite nanoparticles in an aqueous solution.

\section{Experimental Section}

Materials. $\mathrm{FeCl}_{2}+\mathrm{H}_{2} \mathrm{O}(99 \%)$. $\mathrm{FeCl}_{3} 6 \mathrm{H}_{2} \mathrm{O}(98 \%), 1,10-$ 
dibromodecane $(97 \%)$. zirconyl chloride $(98 \%)$, and $2,6-$ lutidine were purchased from Aldrich trietlyy phosplite (97\%) and phosphorous oxyclloride $(98 \%)$ were obtained from Fluka. 1.10-decanediylbisphosphonic acid (DBPA) was synthesized by Michaelis-Arbuzov reaction of $\mathrm{Br}$ $\left(\mathrm{CH}_{2}\right)_{1,} \mathrm{Br}$ and $\mathrm{P}\left(\mathrm{OCH}_{2} \mathrm{H}_{3}\right)_{3}$ as a literature method ${ }^{8 b}$ 4mercaptobutanephosphonic acid (MBPA) was obtained from Prof. Taisun Kim. Hallim University who synthesized it by a literature method. ${ }^{11}$ Slide glass. quartz plate and Si-wafer(ntype. 111) were obtained from Menzel-Glaser. GM glass and Wafernet. respectively. Au substrate of about $2000 \mathrm{~A}$ thickness was prepared by thennal exaporation on Si-wafer with Cr-subcoating. All substrates were cleaned in Piranha solution $\left(98 \% \mathrm{H}_{2} \mathrm{SO}_{1}: 30 \% \mathrm{H}_{2} \mathrm{O}_{2}=3: \mathrm{l} / \mathrm{v}\right)$ for $10 \mathrm{~min}$ and washed with a copious amount of water and dried in a vacuum oven at $50^{\circ} \mathrm{C}$. Acetonitrile was dried by distillation in $\mathrm{P}_{2} \mathrm{O}_{3}$ before use. Deionized water was obtained from Barnstead Nanopure sy stem and was used in all experiemnts.

Apparatus. X-ray diffraction patterns were measured by Rigagu D/Max-2400 X-ray diffractometer with CuK $\alpha$ source and $0.01 \% / \mathrm{sec}$ scan rate. Transmission electron micrograph (TEM) and scanning electron micrograph (SEM) were taken with Jeol JFM 2000fxIl and Hitachi U-4200, respectively. The infrared reflection-absorption spectra were measured by Perkin-Elmer Spectnum 2000 with a variable angle specular reflectance accessory and a $\mathrm{MCT}$ detector. The data were recorded in reflection mode operating with approximately $83^{\circ}$ incident angle and with averaging 2000 scans. Atomic force microscopic (AFM) images were taken by Park Science Instrument Autoprobe $\mathrm{CP}$ in contact mode with a commercial $\mathrm{Si}_{3} \mathrm{~N}_{1}$ cantilever of $0.05 \mathrm{~N} / \mathrm{m}$ force constant. Temperature dependence of magnetization was measured with Lakeshore 7000 ac-magnetic susceptometer at $1 \mathrm{Oe}$. $125 \mathrm{~Hz}$. Magnetizations as a function of applied magnetic field were measured with Lakeshore 7300 vibrating sample magnetometer and Quantum Design MPMS 7 SQUID magnetometer for powder sample and thin film. respectively.

Preparation of Ferrite Nanoparticle and Ferrite/DBPA Multilayer. The synthetic procedure of nanoparticle magnetite was reported in the previous paper. ${ }^{2}$ The only difference is that the synthesis was done in a refrigerated circulating bath at $0^{\circ} \mathrm{C}$. The wet magnetite shurry immediately after synthesis was suspended in water adjusted to $\mathrm{pH}+$. It was sonicated for $20 \mathrm{~min}$ and centrifuged at $10000 \mathrm{rpm}$. The resulting colloidal solution was very stable for several months and used for the multilayer film. In order to prepare magnetite/DBPA multiplaver film. all substrates such as glass. quartz. and Si wafer were first pretreated by being dipped in an anlydrous acetonitrile solution of both $10 \mathrm{mM}$ $\mathrm{POCl}_{3}$ and 2.6-lutidine for an hour. then rinsed with acetonitrile and water and dipped in $20 \mathrm{mM} \mathrm{ZrOCl}_{2}$ aqueous solution for $30 \mathrm{~min}$. Magnetite/DBPA multiplayer was grown layer-by-layer on the substrates by repeating alternate dipping in $5 \mathrm{mM}$ DBPA methanol solution and the magnetite colloidal solution as shown in Scheme 1. The substrate was thoroughly washed with a copious amount of water between immersions. For IR reflection-absorption measurement. Au-

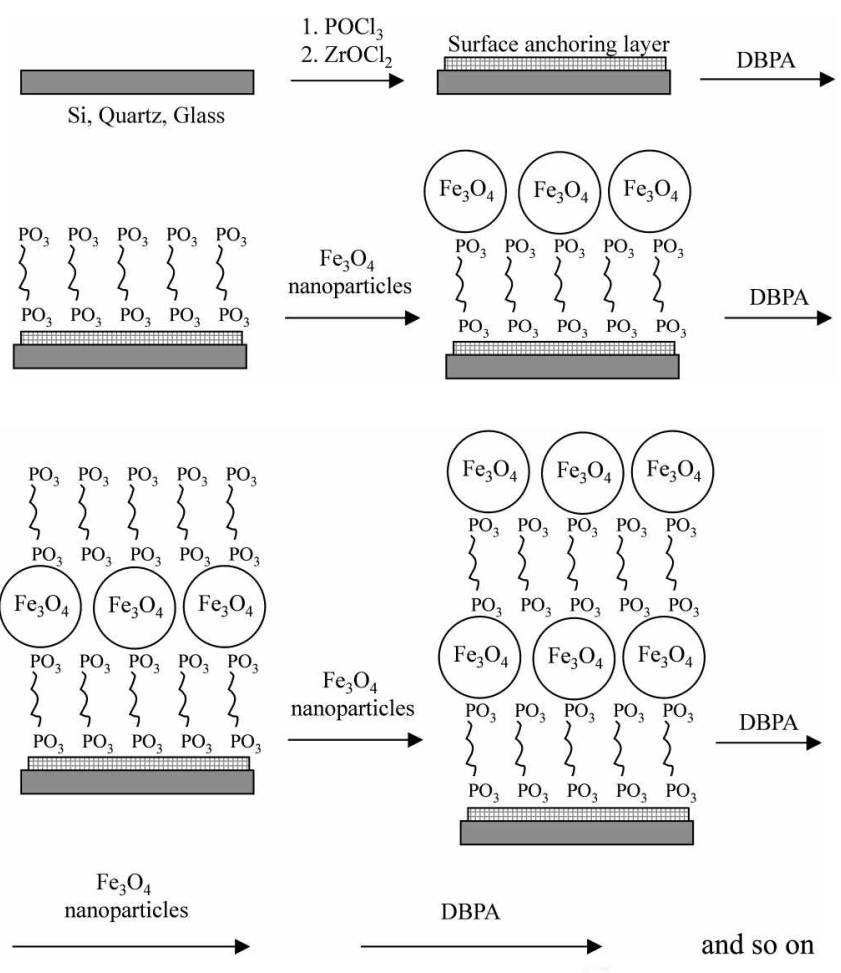

Scheme 1. Schematic representation of preparing territe-nanoparticle/ DBPA multilayer by the self-assembling sequential adsorption method.

coated Si wafer and +-mercaptobutanephosphonic acid were used as a substrate and a surface-anchoring compound. respectively: $:^{5 i k}$

\section{Results and Discussion}

Characterization of Synthesized Magnetite Nanoparticle. Figure I(a) shows the XRD pattern of nanoparticle magnetite which was prepared in an aqueous solution at $0^{\circ} \mathrm{C}$. The data were corrected with background subtraction and smoothed because the signal-to-nose ratio was low due

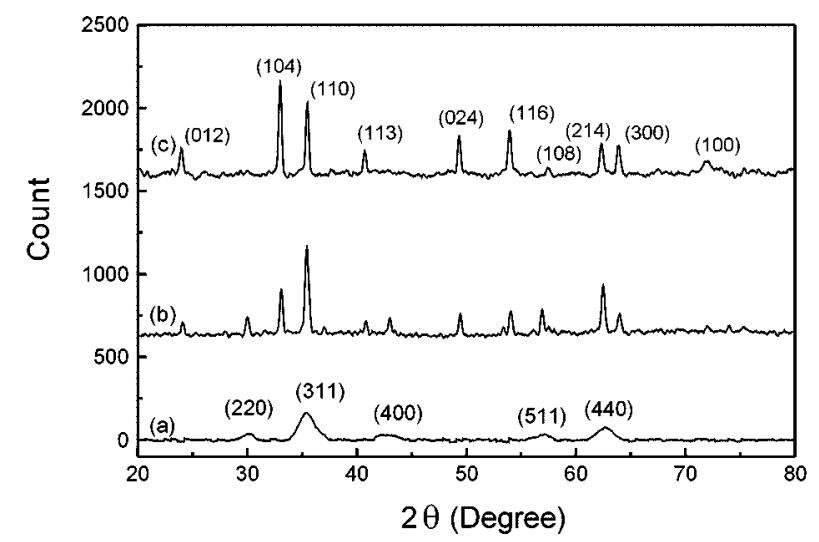

Figure 1. XRD patlon of the synthesizal lemites: (a) as is right after synthesis. (b) the annealod one under vacuum at $506^{\circ} \mathrm{C}$ for 1 hour right atter stonthesis and (c) the amnealed one which had heen exposed to air tor 2 weeks after stuthesis, under vacuum at 500 " $\mathrm{C}$ for 1 hour. 
to the small size and poor crystallinity. The peaks are nearly same to those of the structure of magnetite or maghemite. ${ }^{\text {i. }}$ It is difficult to distinguish magnetite from maghemite by the $\mathrm{XRD}$ pattern because they have the same incerse-spinnel structure and are isomorplic. The unit cell parameter was estimated to be 8.381 using Nelson-Riley extrapolation. This value lies between those of magnetite (8.396) and maghemite $(8.35) .^{14}$ In the previous study ${ }^{15}$ we have shown that magnetite папорагticle of which diameter is about $7 \mathrm{~nm}$ was transforned to maghemite in an ambient condition (air. room temperature). It is expected that the magnetite nanoparticle prepared here will be transformed more easily to maghemite than the nanoparticle of $7 \mathrm{lum}$ in diameter did due to its smaller particle size. Since the clange of XRD pattem is not discernible before and after transformation. we liave sealed the sample in a quartz tube under vacuum and annealed it at $500^{\circ} \mathrm{C}$ for an hour as discussed in the previous study. ${ }^{15}$ Figure $\mathrm{l}(\mathrm{b})$ and $\mathrm{l}(\mathrm{c})$ are the XRD patterns of the annealed one nglit after synthesis and after having been exposed in air for 2 weeks. respectively. While the annealing of magnetite under racuum at $500^{\circ} \mathrm{C}$ gives no phase transfomation. the annealing of maghemite in the same condition will cause the transformation of it to hematite. Figure l(b) shows the XRD pattern of the mixture of magnetite and hematite for the amealed sample that was sealed in vacuum right after synthesis. Figure l(c) shows the pattern of only hematite for the sample that had been exposed to air for 2 week after synthesis and been annealed. Therefore, the nanoparticle fernte was consisted of the musture of magnetite and maghemite right after synthesis and the magnetite was entirely oxidized to maghemite in 2 weeks when it was exposed to air. Although the synthesized ferrite is apparently the muxture of magnetite and maghemute. it might be in only magnetite phase immediately after it was prepared in the reaction solution because the arr-exposure for sample preparation process such as centrifigation could not be completely prevented. The estimated particle size of the ferrite was 2.4 nu in diameter from (311) peak of Figure 1(a) by Debye-Scherrer equation. ${ }^{16}$

Figure 2 shows TEM picture of the synthesized ferrite manoparticle. The shape of particles is round and the sizes

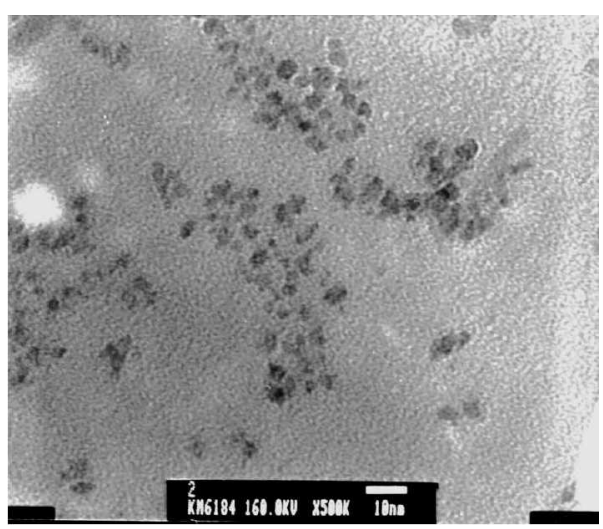

Figure 2. 'JFM picture of the syothesized ferrite namoparticle (scale bat: $10 \mathrm{~mm}$ ). are relatively homogeneous. The estimated average diameter is about $3 \mathrm{~lm}$ from 65 particles in the picture. This value is consistent with the value from XRD peak. This is less than half size of the one previously synthesized with the same method at room temperature. ${ }^{15}$ Although many researchers have reported the synthesis of the namoparticle magnetite or maghemite whose diameter is smaller than $5 \mathrm{~nm} .^{{ }^{-}}$most of them were synthesized in some templates or matrixes such as sol-gel. ${ }^{1^{-1}}$ micelle. ${ }^{1^{-c}}$ nucroemulsion. ${ }^{17 a c e}$ polymers. ${ }^{17 \mathrm{f}}$ block copolymer, ${ }^{l^{-b}}$ and aluminosilicate. ${ }^{1^{-g}}$ In our case. we have synthesized magnetite/maghemite ferrite ${ }^{18}$ whose size is as small as about $3 \mathrm{~nm}$ in diameter in an aqueous homogeneous solution by simply lowenng preparation temperature.

The magnetization of the namoparticle fernte powder as a function of applied magnetic field is shown in Figure 3. Although bulk maghemite and magnetite are ferrimagnetic at room temperature. there is no magnetic hysteresis at room temperature for this fernte. This is charactenstic of superparamagnetic namopaticles where thermal fluctuations are sufficient to overcome the anisotropy energy barrier. ${ }^{20}$ The magnetic moment at the maximum applied field (18 $\mathrm{kOe}$ ) is about $28 \mathrm{emu} / \mathrm{g}$. This value is about one third of that of the saturation magnetization of bulk magnetite. $76 \mathrm{emu} / \mathrm{g} .^{21}$ In the case of single-domain superparamagnetic particles with a fiute size. the relationship between magnetization $(\mathrm{M})$ and applied field $(\mathrm{H})$ at a specific temperature can be described by Langevin function. ${ }^{21}$ Neglecting a size distribution of the namoaprticles, fitting of $\mathrm{M}-\mathrm{H}$ data to Langevin function can give a rough estimation of the size of the ferrite. In this way we obtained the diameter of the ferrite nanoparticle as about 3 run from the fitting of Figure 3. This result is very consistent with those of TEM and XRD.

Figure 4 shows the temperature dependence of ac magnetic susceptiblity $(\mathrm{dM} / \mathrm{dH})$ for the ferrite powder. Ac magnetic susceptiblity is measured in a small oscillating magnetic field without static magnetic field and gives almost the same information as zero-field-cooled data of dc magnetic susceptiblity $(\mathrm{M} / \mathrm{H})$ measured in weak magnetic field. As a temperature decreased, the susceptibility increased until it reached at the maximum at $93 \mathrm{~K}$ and then decreased. The decrease at low temperature is due to the freezing of

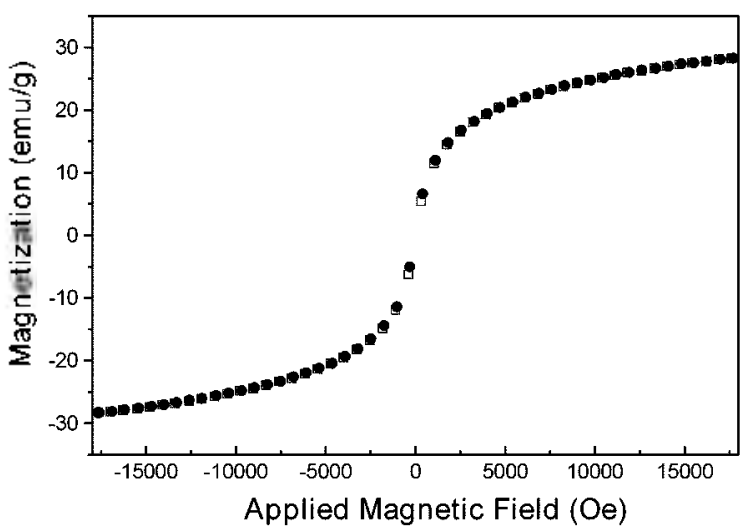

Figure 3. Magnclization ws applied magnetic lickl for the powder of synthesized ferric nanoparticles at room temperature. 


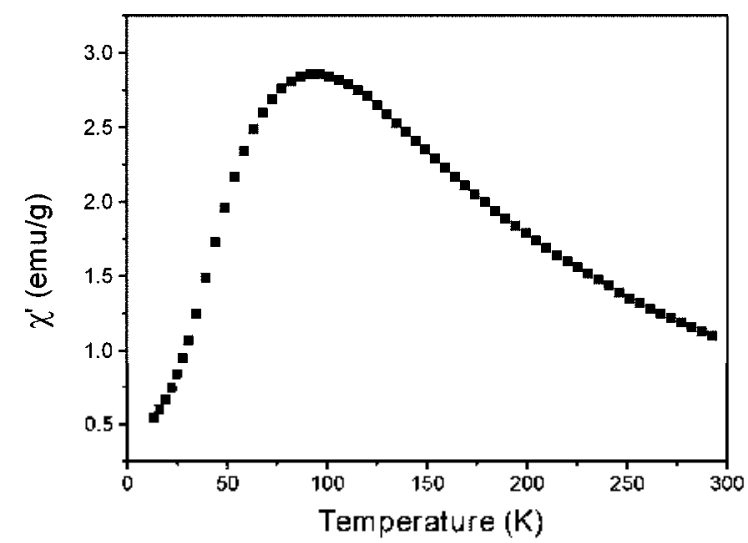

Figure 4 . Temperature-dependent ac magnetic susceptibility for the pour der of synthesized lemite nanoparticles (in-phase component, $\chi^{\prime}$ )

disordered spin system and is usually known in the materials of mictomagnetism and spin glass. ${ }^{-2}$ it is also well known in superparamagnetic nanoparticles because the total magnetic moment is frozen in the process of random agitation by thermal fluctuation. The temperature at a maximum susceptibility $\left(T_{\text {moik }}\right)$ is related to a blocking temperature $\left(T_{B}\right)$ which is a boundary temperature between ferromagnetism and superparamagnetism. $T_{L}$ can be experimentally determined from the temperature where a zero-field-cooled data begins to match with a field-cooled data in dc magnetic susceptibility measurement or where a magnetic hyperfine interaction starts to appear in Mösbauler spectrum..$^{3-3}$ If the particle size is uniform. $T_{\text {tudx }}$ corresponds to $T_{L 3}$ because the splitting of zero-field-cooled data and field-cooled data start at the maximum susceptibility: In the sample with a wide size distribution. the splitting starts at a temperature higher than $T_{\text {trax }}$ and the temperature corresponds to $T_{13}$ of the largest particles in the sample. $T_{\text {ouax }}$ corresponds to average blocking temperature of whole sample. ${ }^{1 " e}$ From the data of Figure 4 , we can estimate the average blocking temperature of the synthesized nanoapticle ferrite powder as $93 \mathrm{~K}$. This value of $T_{12}$ is relatively higher than those reported for nanoparticle maghemites which were synthesized in a similar size with some templates. IFlaci

Nanoparticle-Ferrite/DBPA Complex Multilayer. As shown in Scheme 1 . we constructed organic/inorganic composite multilayer by stacking DBPA layer and ferrite nanoparticle layer alternately. The driving force of layer stacking is the strong adsorption of phosphonnate to the surface of metal oxide as mentioned in lntroduction. The surface anchoring to the substrates such as glass. quartz, and Si wafer which have hy roxyl group on its surface was done by a direct phosphorylation with $\mathrm{POCl}_{3}$ and a subsequent zirconation with $\mathrm{ZrOCl}_{2}$ without using anchoring aminosilane compound Katz ef al. used. ${ }^{-7}$ This initial anchoring step was not so critical that DBPA molecule could be directly adsorbed on the substrates as reported in our other study: Only the surface coverage in the case of without anchoring step was slightly lower than that with the step.

UV-Vis absorption spectra of the ferrite/DBPA multiplayer on a quartz plate are shown in Figure 5. The absorption is

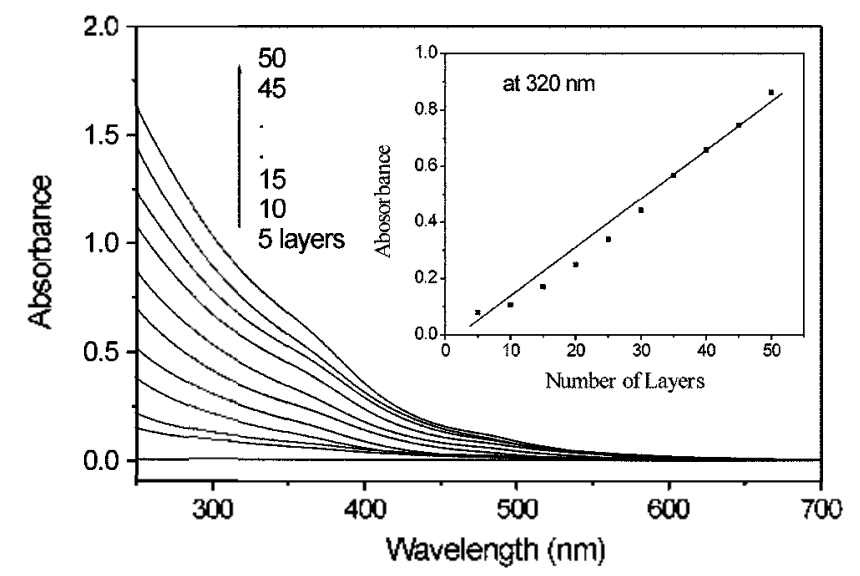

Figure 5. UV-Vis absorption spectra of the territe/DPPA multiplayer on a quart? substrate. The inset shows the absorbance $v$ number of layers at $320 \mathrm{~mm}$.

due to only ferrite nanoparticles since DBPA does not absorb visible light. The feature of absorption spectrum is the same as that of the colloidal solution of the manoparticle ferrite (not shown here). The multiplayer film is considerably transparent for visible light compared with bulk maghemite due to the size quantization effect. ${ }^{\Upsilon 6}$ As shown in the inset graph. the absorption linearly increases as the number of layer increases. This means that the amount of the nanoparticle ferrites included in each layer is somewhat uniform.

In order to confirm the systematic increment of DBPA layer we measured infrared reflection-absorption spectra of ferrite/DBPA multiplayers. The layers were deposited on gold surface on Si-wafer using MBPA as an anchoring agent. Figure 6 shows IR absorption bands of $\mathrm{CH}_{2}$-stretching vibration in the multiplayer. The absorption peaks appear at 2925-2931 $\left(v_{\mathrm{ak}}\right)$ and $2852\left(v_{\mathrm{s}}\right) \mathrm{cm}^{-1}$. which correspond to asymmetric and symmetric stretching, respectively. The inset shows that the integrated peak-areas increased relatively linearly as the number of layer increased. Therefore DBPA layer also systematically increases as well as the layer of

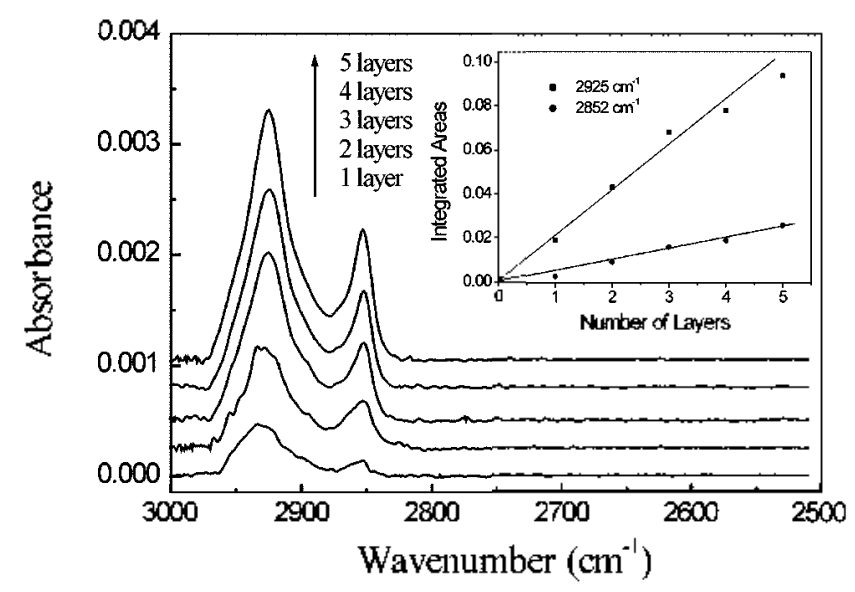

Figure 6. Reflection-absontion IR spectra of the territe/DPPA layers on a gold substrate. The inset shows the integrated peak area is number of layers. 
nanoparticles do as shown in UV-Vis absorption. The peak position and widths (about 40 and $20 \mathrm{~cm}^{-1}$ at $v_{k \text { is }}$ and $v_{\mathrm{s} \text {. }}$ respectively) are almost coincident with those of Zr-DBPA multiplayer film $\left(+1\right.$ and $23 \mathrm{~cm}^{-1}$ at $2929\left(v_{\mathrm{as}}\right)$ and $28.54\left(v_{\mathrm{s}}\right)$ $\mathrm{cm}^{-1}$. respectively) ${ }^{*}{ }^{*}$ Since the peak position and width did not change appreciably as a new layer added. the degree of ordering of each layer may be relatively constant. The comparison of these data with a polycrystalline and an amorphous-like $\mathrm{Zr}$-DBPA ${ }^{\text {*il }}$ show that the structural ordening of DBPA in ferrite/DBPA multiplayer is pretty close to that in Zr-DBPA multiplayer.

The surface morphologies of ferrite/DBPA multiplayer were inrestigated by AFM. Figure 7 shows AFM images of bare slide glass and 5-layer ferrite/DBPA film. The deposition of film does not result in drastic morphology cliange on the glass substrate. The surface of bare slide glass looks consisted of round particles of $0.1-0.15 \mu \mathrm{m}$ in diameter. However, the height difference is relatively small as maximum $12 \mathrm{~nm}$. When the 5 layers of ferrite/DBPA were deposited, the particle-like surface was simply increased in diameter and the depth also slightly increased. A rootmean-squared roughness of bare glass and the film were $2 \mathrm{l}$ and $38 \mathrm{~A}$. respectively. Figure 8 shows AFM images of DBPA- and nanoparticle-terminated surfaces in nm scale. In this case. the multilayer was constructed on the surface of Siwafer in order to confirm the flatness of substrate surface. The repeated measurements of different regions in one
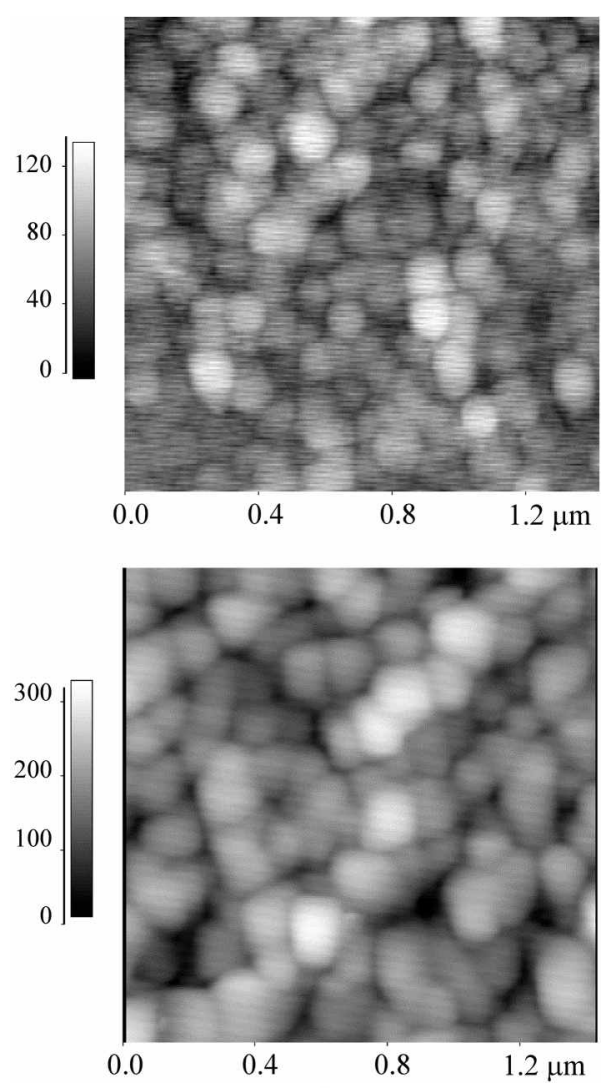

Figure 7. AFM images of the territe/DBPA byers on a glass substrate (top: bare glass substrate, bottom: aller deposition of Iemite/DBPA 5 lavers).
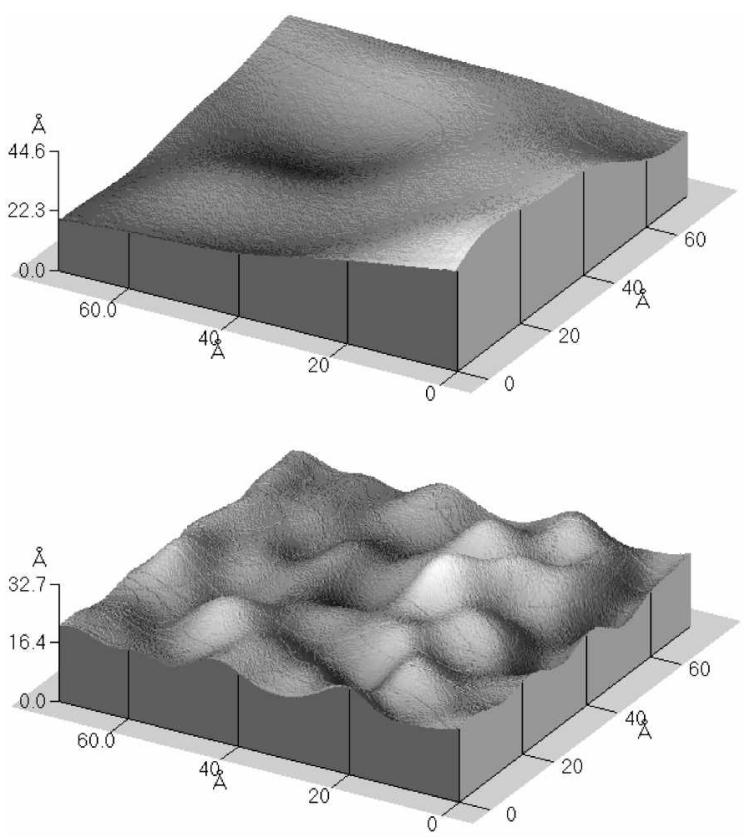

Figure 8. AFM images of 20 layers of the ferrite/DBPA on $\mathrm{Si}$ thales (lop: the surlace was leminated ath DBPA, bottom: leminaled with lerrite nanoparticles)

Sample and a few samples gave relatively a consistent result. While the surface is smooth and flat when it is terminated with DBPA, the image of the surface shows hills and valleys and looks consisted of small particles of $2-3 \mathrm{~nm}$ in diameter when terminated with ferrite nanoparticles. Therefore. a stepwise construction of DBPA layer and nanoparticle layer. which is not randonly mixed together. was clearly seen. Figure 9 shows a SEM picture of side-cut view of the DBPA/ ferrite 50-layer film on glass substrate. Although the picture is not so good. the multiplayer is clearly differentiated from the substrate. The thickness of the film is fairly uniform and is estimated as about $280 \mathrm{~mm}$. The average thickness of each layer (DBPA + ferrite) can be estimated as about 5-6 $\mathrm{lm}$. It can be concluded that each layer is consisted of the single particle and the single DBPA layers since the length of DBPA is roughly $2 \mathrm{~mm}^{2^{-}}$and the diameter of a ferrite

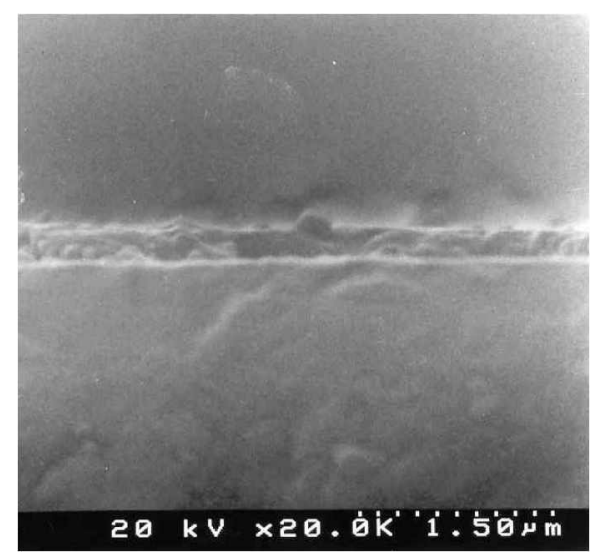

Figure 9. Side-cut view of SLM images of the ferrild/DBPA 50 layers on a glass substrale (scale bar: $1.5 \mu \mathrm{m}$ ). 


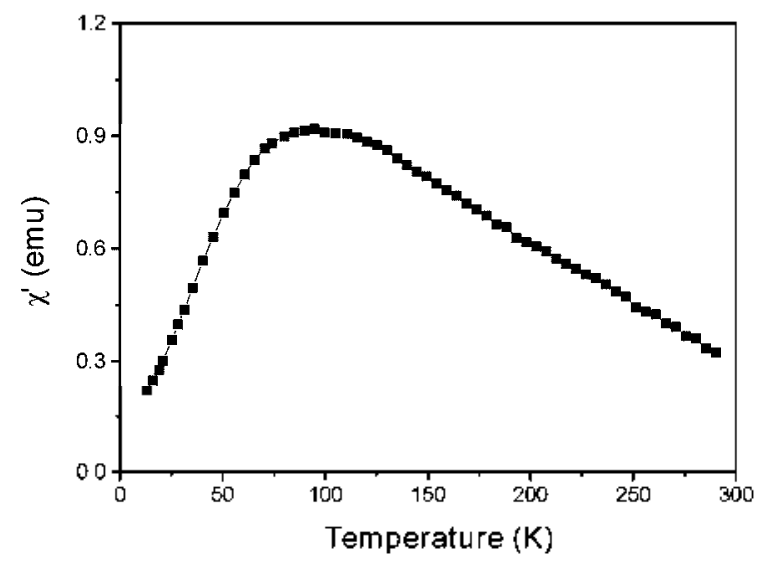

Figure 10. lempersature dependent ac magnestic susceptibility for the femite/DBPA multiplayer on olass substrate. (100) lavers of ferrite/DBPA were scraped off from olass substrate for the matasurement).
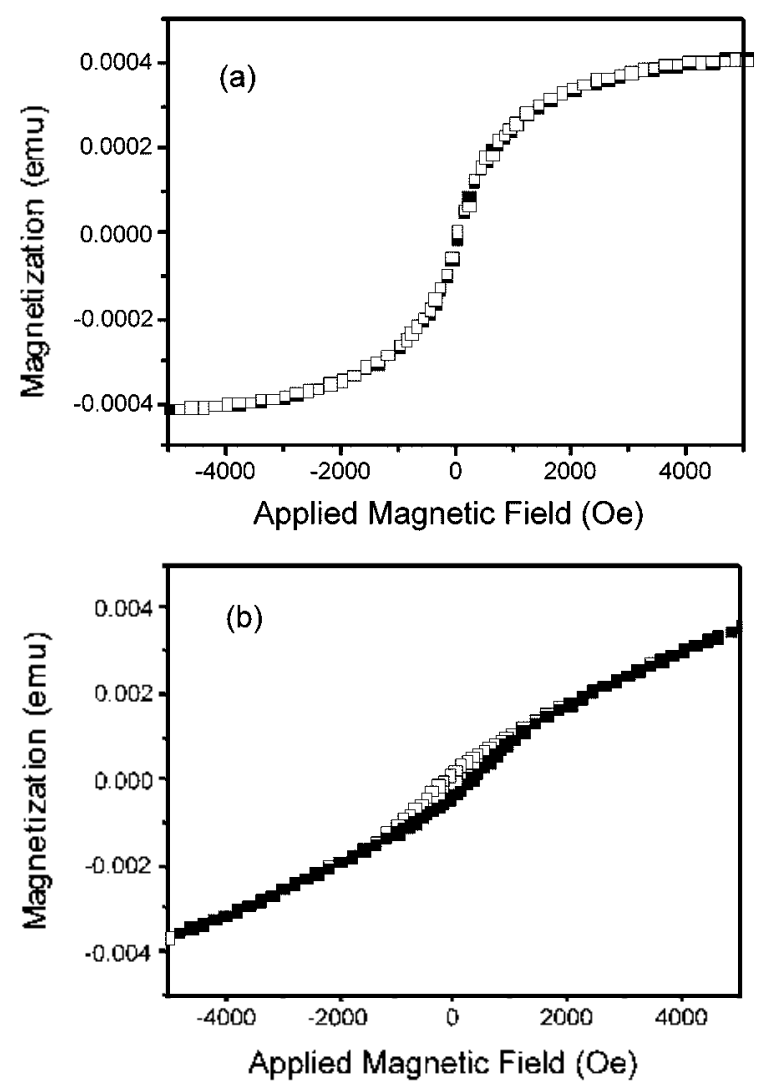

Figure 11. Magnetization vs, applicd magnelic ficld for the ferrite DBPA multiplayer on glass substrate at room temperature (100) layets, (a) at $300 \mathrm{~K}$, (b) at $2 \mathrm{~K}$ ).

nanoparticle is about $3 \mathrm{~mm}$.

The magnetic properties of the ferrite/DBPA multiplayer film were investigated with the measurements of magnetization ss. applied magnetic field and temperature dependence of ac magnetic susceptibility: Figure 10 shows the temperature dependence of ac magnetic susceptibility for the 100 layvers of ferrite/DBPA prepared on slide glass. The sample film used here was scraped off from the substrate with a doctor blade due to a difficulty of measurement.
Figure 11 shows the changes of magnetization as a function of applied field for the same sample that is not scraped off. which is measured at $300 \mathrm{~K}$ and $2 \mathrm{~K}$ with SQUID magnetometer. The results are almost the same as those of nanoparticle ferrite powder shown in Figure 3 and 4 . As discussed in previous section, the ferrite/DBPA film is also superparamagnetic at room temperature and its blocking temperature is about $90 \mathrm{~K}$. Small lyystereris appeared on the plot of magnetization $v s$ applied field at the temperature of $2 \mathrm{~K}$ which is below the blocking temperature. At this temperature, the film became ferrimagnetic with coercivity of $240 \mathrm{Oe}$.

\section{Conclusion}

Ferrite-nanoparticle/alkyl-bisphosphonate complex multiplayer was prepared by self-assembling sequential adsorption method which is an analogy of metal bisphosphonate multiplayer. In this method. the coordination between metal ions and phosphonates was replaced with the adsorption of alkyl bisphosphonate to the surface of metal oxide. The multilayer could be grown up to more than lo0 layers by simple alternate dips in the constituent solutions at an ambient condition. The data of UV-Vis and IR absorption and AFM and SEM pictures confirm that the growth of multilayer was very systematic. Each repeating unit layer was consisted of almost single namoparticle layer and DBPA layer. The multiplayer film was mechanically robust and stable. The magnetic properties of the film are same to those of the nanoparticle ferrite powder which is superparamagnetic at room temperature. Since a phosphonic-acid derivative can be strongly adsorbed on the surfaces of most of metal oxides. this multiplayer techuique can be easily applied to most of metal-oxide namoparticles. We are now investigating the complex multiplayer of semiconducting nanoparticles such as $\mathrm{TiO}_{2}$ and $\mathrm{SnO}_{2}$.

Acknowledgement. This work was supported by Basic Science Research Institution Program of Ministry of Education (BSRI-97-2455) and Korea Research Foundation Grant (KRF-2000-015-DP0298). The authors thank Professor Taisun Kim (Hallym University) for providing us with 4mercaptobutanephosphonic acid.

\section{References}

1. Fendler, J. I1. Nemopaticle's and Vawstructured Films: Preparation, (haractetization and tpplications: Wiley-VCl: Weinhein. 1998.

2. Henglein. A. Chem Rew 1989. 89. 1861. (b) Hatheldt. A.: Grätzel. M. Chem. Rev 1995. 95. 49. (c) Alivisatos. A. P. Science 1996, 271, 9.3.3. (c) Nanoaprticle's in Solids and Solntions: Fendler, J. It.; Dekany, I., F.d: Kluwer Academic: Dordrecht, 1996.

3. Adair. J. H.: Li. T.: Kido. T.: Harey: K.: Moon. J.: Mecholsky: I.: Morrone. A.: Talham. D. R.: Ludwig. M. H.: Wang. L. Hater Sci. Eng. R 1998. R23. 139 .

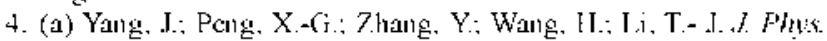
(Wem. 1993, 97, 4484. (h) Meldrum, F. C.: Kotox. N. A.; Fendler; 
J. H. J. Phys. Chm. 1994. 98, 4506. (c) Nakaya. T.: Li. Y.-J.: Shibata. K. J. Hoter Chem. 1996. 6.69l. (d) Kang. Y. S.: Lee. D. K.: Stroeve. 1'. Thin Sold thim. 1998. 327-329.541.

5. (a) Cassagneau, T: Fendler. J. I1. J. Phs. Chem. B 1999. 103. 1789. (b) Caruso. F.: Spasova. M.: Susha. A.: Giersig. M.: Caruso. R. A. Chem. Mater 2001, 13. 109. (c) Gittins. D. I.: Susha. A. S.: Schoeler. B.: Caruso. F. Adw: Mater 2002, 14. 508. (d) Dai. J.: Bruening. M. L. Aano Lett. 2002. 2. 497.

6. (a) Brust. M.: Etchenique. E. J.: Gordillo. (j. J. Ch'm. Commm. 1996. 1950. (b) Musick. M. D.: Keating. C. D.: Kecte, M. II.: Nathan, M. J. (hem. . Fater 1997, 9, 1499. (c) Nakanishi, T.: Ohtani, B.: Uosaki, K. J. Phys. (hem. 1998, 102.157I. (d) IHu, K.: Brust. M.: Bard. A. J. Chem. Mutem 1998. 10. 1 160. (e) Brust. M.: Bethell. D.: Kiely. C. J.: Shillin. D. J. Langmmir 1998. I4. 5425. (1) Sarathy. V. K.: Thomas. l' J.: Kulkami. G. U.: Rao. C. N. R. J. Phs ('hem. 1999, J03. 399

7. Gaines Jr. G. I. Insoluble Womolaners at Liquid-Gas Interfaces; Wiley Interseienes: New York. 1966.

8. (a) Lee. H.: Kepley. L. I.: Hong. H.-G.: Mallouk. T. E. J. Am. Chem. Soc. 1988. H10.618. (b) Lee. H.: Kepley. L. I.: Hong. H.G.: Akhter. S.: Mallouk. T. E. J. Phns. Chm. 1988. 92. 2597. (c)

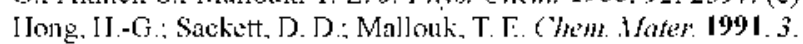
521. (d) Yang. II. C.: Noki, K.: IHong. II.-G.: Sackett, D. D.: Arendt. M. F.: Yau, S.-J Bell. C. M.: Mallouk. T. Г. . J. im. Chem. Sere, 1993. 115. 11855.

9. (a) Pechy: P': Rolzinger. F. P:: Nazeeruddin. M. K.: Kohle. O.: Zakeeruddin. S. M.: Humphri-Baker. R.: Grälcel. M. J. Chem. Soc. (hem. Commm 1995, 65. (b) Yan, S. G.: I Iupp. I. T. J. Phls. (7thm. 1996, 100,6867. (c) Trammel], S. A.: Wimbish. J. C.: Odobel, F.: Gallagher, J.. A.: Narula, P. M.: Meyer. T. J. J. Im. Chem. Suc. 1998. 120. 13248. (d) Lee. M. S.: Shim. H. K.: Kim. Y. I. Hot Crest. Liq. Crast. 1998. 316.401

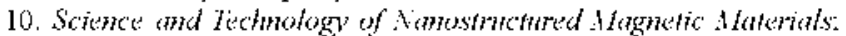
I Iadjipanayis, G. C.: Primz, G. A., F.ds.: Plenum: Now York, 1991.

11. Ilong. II.G.: Mallouk. T. F. Langmmir 1991, 7, 2.362 .

12. Kang. II.: I.ee. C. S.: Kim, D.: Kang. Y. S.: Kim. Y. I. Bull Konean Chem. Sor. 1998. 19. 408.

13. Come1l. R. M.: Scliwertmann. U. The Iron Oxidss. VCH: New York. 1996: p 167.

14. JCPDS (Joint Committee on Powder Diftraction Standards) data base $19-629$ and $39-1246$.

15. Kang, II.: I.ce, C. S.: Kim, D.: Kang. Y.S.: Kim, Y. I. Bull Konzan Chem. Soce. 1998. 19.408

16. Azarilit. L. B. The Powder thethod Megraw Hill: New York. 1958.

17. (a) Kommatedd, N. S.: Tata, M.: Jolm, V. T.: McPherson, G. I.: J Jeman, M. F.: J.e., Y. S.: OComnor J:: Akiara, J. A.: Kaplan, D.
L. Ch'm. Mathe 1946. 8. 801. (b) Soln. B. H.: Cohen. R. E. Chem. Mat'r. 1997. 9. 264. (c) F'eltin. N.: H'ileni. M. P'. Langmair 1997. 13.3927. (d) Zhang. L.: l'apaelthymiou. G. C.: Ying. I. Y. J.

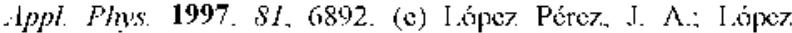
Quintela M. A.: Mira, J.: Riras, J.: Charles, S. W. J. Phus. (Them. B 1997, 101. 8045. (t) Pardope. II.: Chua-atnusom, W: St. Pierre, I. G.: Dobson. J. J. Hagn. Hagm. Hakr 2001. 225. 41. (g) Zhang. L.: P'apael thymion. (i. C.: Ying. J. Y.: J. Dhts. Chem. B 2001. 105 . 74l4. (h) Hveon. T:: Lee. S. S.: l'ark. I.: Chung. Y.: Na. H. B. J. in. (hem Soc 2001. 123. 12798. (i) Yadong. Y. I.: Mayers. B. T.: Xia. Y. Woho letett. 2002, 2. 183

18. We call the magnetic nanoparticle as simply "ferrite" in the rest discussion. since the nanopaticle was consisted of both mannetite and maghemile by partial transtomation.

19. The manuscript of a temperature-controlled synthesis of nanoparticle magnetite and characterization of their magnetic propertics is in preparation.

20. Gunther. I. In Magnetic Properties of Fine Partickes: Dormant. I. L.: Fiorani. D.. Eds.: Wiley: Nen York. 1992: p 213.

21. Cullity. B, D. In Introduction to Magnetic Materials. AddisonWesley: Reading. MA. 1972: p 201 .

22. Chikazumi, S. Phusics of Fenwmagnetism, Clarendon Press: Oxford, 1997: p 153

23. Chien, C. I.. In Science and Technologv of Wanostnctured Magnefic Matrials. Hajipanayis. G. C.: Prinz. G. A.. Eds.: l'lenum l'ress: New York. 1991: p 477.

24. (a) Kalz. H. E.: Scheller. G.: P'ulvinski. T. M.: Schilline. M. L.: Wilson, W. I..: Chidsey, C. F. D. Science 1991, 25t. 1485. (b) Katz. II. F.: Schilling. M. I..: Chidsey, C. F. D.: Puttinsti, T. M.: Ilutton, R. S. Chem Hater: 1991, 3. 699. (c) Ungashe, S. B.: Wilson. W. L.: Kutz. H. E.: Scheller. (i. R.: P'ulvinski. T. M. $J$. Am. Chem. Soc. 1992. 114.8717. (d) Kalc. H. E.: Schilline. M. L. Chem. Hater 1993. 5. 1162. (e) Katz. H. E. Chem. Hater 1994. 6. 2227. (t) Xu, X.II.: Yang. II. C.: Mallouk, T. F..: Bard. A. J. J. in. (hem. Soc 1994. 116. 8386. (g) Vermeulen, I. A.: Thompson, M. Г. Nature 1992. 358. 656. (h) Chac. H. J.: I.ce. M. S.: Kim. Y. I.: Lee. H. Bull Non $(\%$ tm. Soc. 1998. 19. 27. (i) Lee. M. S.: Shim. H. K.: Kim. Y. I. Nol C'nust. Liq. Cryst. 1998. 316. 179 .

25. Cho, K. J.: Shim. H. K.: Kim. Y. I. Sin. Wetals 2001. //7, 153.

26. 7.iolo, R. F.: Giannelis. F. P.: Weinstein, B. A.: OItoreo, M. P.: Ganguly. B. N.: Mehrotra. V: Russell. M. W: Hullinar. D. R. Scrimce 1992. 257.219.

27. Since $\angle r-D B P A$ has $17.3 \AA$ of crystallographic layer spacing in a tilted structure. ${ }^{s}$ we have ronghly assumed it.

28. Dines, M. B.: DiGiacomo. P. M. Ihorg. (he'm. 1981. 20.92. 